\title{
Synthesis of 4-aryl-4,5-dihydro-1H-indeno[1,2-d]pyrimidines by Biginelli condensation and their antibacterial activities
}

\author{
RAMANDEEP KAUR ${ }^{\mathrm{a}}$, MONIKA BANSAL ${ }^{\mathrm{a}}$, BALBIR KAUR $^{\mathrm{a}, *}$, TULIKA MISHRA $^{\mathrm{b}}$ and \\ ARUNA BHATIA ${ }^{b}$ \\ a Department of Chemistry, ${ }^{b}$ Department of Biotechnology, Punjabi University, Patiala 147002, India \\ e-mail: aries_balbir@yahoo.co.in
}

MS received 22 September 2010; revised 4 March 2011; accepted 9 March 2011

\begin{abstract}
A simple and efficient method has been developed for the synthesis of series of 4-aryl-1,3,4,5tetrahydro- $2 \mathrm{H}$-indeno[1,2- $d$ ] pyrimidine-2-thiones through Biginelli's one-pot multicomponent condensation reaction via microwave irradiations. Then, these thiones were converted to their S-alkylated/aralkylated derivatives. The prepared heterocyclic products were structurally confirmed by analytical and spectral data and evaluated for their antibacterial activities. The results showed that this skeletal framework exhibited marked potency as antibacterial agents. The compound 2-(Ethylthio)-4-(4-Hydroxy-3-methoxyphenyl)-4,5-dihydro$1 H$-indeno[1,2- $d$ ] pyrimidines $4 \mathrm{~b}$ have shown antibacterial activity towards all the seven clinical isolates used.
\end{abstract}

Keywords. Indeno[1,2- $d]$ pyrimidine-2-thiones; multicomponent reaction; microwave irradiation; antibacterial activity.

\section{Introduction}

In 1893, Pietro Biginelli reported ${ }^{1}$ the first synthesis of 3,4-dihydropyrimidin-2(1H)-ones by a one-pot cyclocondensation of an aromatic aldehyde, ethylacetoacetate and urea in ethanolic solution through thermal heating. In recent years, the interest in dihydropyrimidines (DHPMs) has increased rapidly because of the structural resemblance of DHPMs with clinically important Hantzsch pyridines. ${ }^{2-4}$ The biologically active dihydropyridine molecules contain the substituent 4-phenyl ring positioned above and in vertical plane of 1,4-dihydropyridine ring, which itself is a flattened boat conformation. ${ }^{5}$ The solid state structure of dihydropyrimidine analogues shows that they can adopt a conformation which is similar to reported conformation of dihydropyridine calcium channel blockers. ${ }^{2,6}$ Literature study reveals that pyrimidines exhibit wide range of biological activities ${ }^{7}$ like antibacterial, antiviral, antitumoral and antiinflammatory actions. Also, they can act as calcium channel blockers and antihypertensive agents. ${ }^{8}$ In view of this, we have synthesized a series of Quinazolinethiones and Quinazolinethioethers using $\alpha$-tetralone, ${ }^{10}$ a cyclic ketone, as an active methylene compound. In the present paper, we are reporting the work with 1-indanone, synthesizing indeno

*For correspondence $[1,2-d]$ pyrimidine-2-thiones via microwave irradiations and thermal heating. While going through the literature, it was found ${ }^{9}$ that indeno[1,2-d]pyrimidine2-thiones were unknown in the literature except for a report mentioning a compound 4-phenyl-4,5-dihydro$1 H$-indeno[1,2- $d$ ]pyrimidin-2(3H)-thione. Further, the $S$-alkylated/aralkylated derivatives of indeno[1,2- $d]$ pyrimidine-2-thiones were prepared. A series of prepared compounds were, then, evaluated for antibacterial activities. The upsurge of widespread multidrug resistance microorganisms such as Escherichia coli, ${ }^{11,12}$ Staphylococcus epidermidis, ${ }^{13,14}$ Staphylococcus aureus, ${ }^{15}$ Pseudomonas aeruginosa ${ }^{16}$ had been reported as a major threat to human health. In view of this occurrence of microorganisms' resistance to drugs currently in use and emergence of new diseases, there is a continuous need for the synthesis of new organic compounds as potential antibacterial agents using a fast and efficient approach. Thus, it is conceivable to develop a series of indenopyrimidine thioethers with the aim of investigating their antibacterial properties.

\section{Experimental}

Melting points were determined in open end capillaries and are uncorrected. Compounds were checked for 
their purity by TLC on silica gel G plates and spots were located by iodine vapors. ${ }^{1} \mathrm{H}$ NMR spectra were recorded on BRUKER ADVANCE II 400 NMR Spectrometer using TMS as internal standard. The mass Spectra were obtained on a JEOL $5 \times 102 / \mathrm{DA}-6000$ mass spectrometer. The IR spectra were recorded on Perkin-Elmer spectrum RX IFT-IR System using $\mathrm{KBr}$ pellets. The microwave irradiated reactions were performed in domestic household microwave oven Samsung M177N.

\subsection{General procedure for the synthesis of 4-aryl -1,3,4,5-tetrahydro-2H-indeno[1,2-d]pyrimidine-2- thiones}

A mixture of 1-indanone ( 0.01 mole, $1.32 \mathrm{~g})$, thiourea $(0.01$ mole, $0.76 \mathrm{~g})$ and substituted aromatic aldehyde ( 0.01 mole) were irradiated in microwave for 2-8 min using abs. alcohol $(5 \mathrm{~mL})$ as energy transfer medium and $\mathrm{HCl}$ (3-4 drops) as a catalyst. In the second procedure, the same reaction mixture was refluxed for 4 $6 \mathrm{hrs}$. The reaction mixture on standing for a few hours afforded product which was filtered under reduced pressure and recrystallized out of alcohol. The products were characterized on the basis of melting points, IR, NMR, mass and elemental analysis spectra. The spectral data is given below.

2.1a 4-(4-Methoxyphenyl)-1,3,4,5-tetrahydro- $2 \mathrm{H}$ indeno[1,2-d]pyrimidine-2-thione (1): IR $(\mathrm{KBr}$, $\left.\mathrm{cm}^{-1}\right)$ : $3424.0(\mathrm{NH}), 1170.8(\mathrm{C}=\mathrm{S}) ;{ }^{1} \mathrm{H}$ NMR $(\delta$, ppm): 8.23 (s, 1H, NH), 7.93 (s, 1H, NH), 6.96-7.80 $(\mathrm{m}, 8 \mathrm{H}, \mathrm{Ar}-\mathrm{H}), 6.84\left(\mathrm{~s}, 1 \mathrm{H}, \mathrm{H}_{A}\right), 4.00\left(\mathrm{~s}, 2 \mathrm{H}, \mathrm{C}_{6} \mathrm{CH}_{2}\right)$, 3.88 (s, 3H, $\mathrm{OCH}_{3}$ ); Mass (m/z):308 $\mathrm{M}^{+}, 307,262$, 249; Anal. Calcd for $\mathrm{C}_{18} \mathrm{H}_{16} \mathrm{~N}_{2} \mathrm{SO}$ : C 70.12, H 5.19, N 9.09. Found: C 70.01, H 5.10, N 9.01\%

$2.1 \mathrm{~b}$ 4-(3-Nitrophenyl)-1,3,4,5-tetrahydro-2H-indeno [1,2-d] pyrimidine-2-thione (2): IR $\left(\mathrm{KBr}, \mathrm{cm}^{-1}\right)$ : $3437.2(\mathrm{NH}), 1173.1(\mathrm{C}=\mathrm{S}) ;{ }^{1} \mathrm{H}$ NMR $(\delta, \mathrm{ppm}): 10.84$ $(\mathrm{s}, 1 \mathrm{H}, \mathrm{NH}), 8.90(\mathrm{~s}, 1 \mathrm{H}, \mathrm{NH}), 7.18-8.51(\mathrm{~m}, 8 \mathrm{H}, \mathrm{Ar}-$ $\mathrm{H}), 5.68\left(\mathrm{~s}, 1 \mathrm{H}, \mathrm{H}_{A}\right), 4.13\left(\mathrm{~s}, 2 \mathrm{H}, \mathrm{C}_{6} \mathrm{CH}_{2}\right)$; Anal.Calcd for $\mathrm{C}_{17} \mathrm{H}_{13} \mathrm{~N}_{3} \mathrm{SO}_{2}$ : C 63.16, $\mathrm{H}$ 4.02, N 13.00. Found: $\mathrm{C}$ $63.05, \mathrm{H} 3.98, \mathrm{~N} 12.97 \%$

2.1c 4-(2,3-Methylenedioxyphenyl)-1,3,4,5-tetrahydro2H-indeno[1,2-d]pyrimidine-2-thione (3): $\mathrm{IR}(\mathrm{KBr}$, $\left.\mathrm{cm}^{-1}\right)$ : $3432.1(\mathrm{NH}), 1183.5(\mathrm{C}=\mathrm{S}) ;{ }^{1} \mathrm{H}$ NMR $(\delta, \mathrm{ppm})$ : $8.50(\mathrm{~s}, 1 \mathrm{H}, \mathrm{NH}), 6.77-7.62(\mathrm{~m}, 8 \mathrm{H}, \mathrm{Ar}-\mathrm{H} \& \mathrm{NH})$, $6.06\left(\mathrm{~s}, 2 \mathrm{H}, \mathrm{O}-\mathrm{CH}_{2}-\mathrm{O}\right), 5.42\left(\mathrm{~s}, 1 \mathrm{H}, \mathrm{H}_{A}\right), 4.01(\mathrm{~s}, 2 \mathrm{H}$,
$\mathrm{C}_{6} \mathrm{CH}_{2}$ ); Anal.Calcd for $\mathrm{C}_{18} \mathrm{H}_{14} \mathrm{~N}_{2} \mathrm{SO}_{2}$ : C 67.08, H 4.35, N 8.69. Found: C 67.05, H 4.42, N 8.34\%

2.1d 4-(4-Hydroxy-3-methoxyphenyl)-1,3,4,5-tetrahydro-2H-indeno [1,2-d]pyrimidine-2-thione (4): IR $\left(\mathrm{KBr}, \mathrm{cm}^{-1}\right): 3301.1(\mathrm{NH}), 3542.0(\mathrm{OH}), 1105.5$ $(\mathrm{C}=\mathrm{S}) ;{ }^{1} \mathrm{H}$ NMR $(\delta, \mathrm{ppm}): 8.29$ (s, $\left.1 \mathrm{H}, \mathrm{NH}\right), 8.11$ (s, $1 \mathrm{H}, \mathrm{OH}) ; 7.07-8.20(\mathrm{~m}, 8 \mathrm{H}, \mathrm{Ar}-\mathrm{H} \& \mathrm{NH}), 5.91$ (s, $\left.1 \mathrm{H}, \mathrm{H}_{A}\right), 4.14\left(\mathrm{~s}, 2 \mathrm{H}, \mathrm{C}_{6} \mathrm{CH}_{2}\right), 3.98\left(\mathrm{~s}, 3 \mathrm{H}, \mathrm{OCH}_{3}\right)$; Anal.Calcd for $\mathrm{C}_{18} \mathrm{H}_{16} \mathrm{~N}_{2} \mathrm{SO}_{2}$ : C 77.77, H 4.94, $\mathrm{N}$ 8.64. Found: C 77.72, H 4.87, N

2.1e 4-(4-Nitrophenyl)-1,3,4,5-tetrahydro-2H-indeno [1,2-d]pyrimidine-2-thione (5): IR $\left(\mathrm{KBr}, \mathrm{cm}^{-1}\right)$ : $3436.1(\mathrm{NH}), 1181.5(\mathrm{C}=\mathrm{S}) ;{ }^{1} \mathrm{H}$ NMR $(\delta, \mathrm{ppm})$ : $9.96(\mathrm{~s}$, $1 \mathrm{H}, \mathrm{NH}), 8.64(\mathrm{~s}, 1 \mathrm{H}, \mathrm{NH}), 7.12-8.80(\mathrm{~m}, 8 \mathrm{H}, \mathrm{Ar}-\mathrm{H})$, $5.67\left(\mathrm{~s}, 1 \mathrm{H}, \mathrm{H}_{A}\right), 4.10\left(\mathrm{~s}, 2 \mathrm{H}, \mathrm{C}_{6} \mathrm{CH}_{2}\right)$; Anal.Calcd for $\mathrm{C}_{17} \mathrm{H}_{13} \mathrm{~N}_{3} \mathrm{SO}_{2}$ : C 63.16, H 4.02, N 13.00. Found: C $63.10, \mathrm{H} 4.00, \mathrm{~N} 12.99 \%$

$2.1 \mathrm{f}$ 4-(2-Methylphenyl)-1,3,4,5-tetrahydro-2H-indeno [1,2-d]pyrimidine-2-thione (6): $\mathrm{IR} \quad\left(\mathrm{KBr}, \mathrm{cm}^{-1}\right)$ : $3401.1(\mathrm{NH}), 1185.2(\mathrm{C}=\mathrm{S}) ;{ }^{1} \mathrm{H}$ NMR $(\delta, \mathrm{ppm}): 9.01$ $(\mathrm{s}, 1 \mathrm{H}, \mathrm{NH}), 8.24(\mathrm{~s}, 1 \mathrm{H}, \mathrm{NH}), 7.07-8.11(\mathrm{~m}, 8 \mathrm{H}, \mathrm{Ar}-$ $\mathrm{H}), 5.27\left(\mathrm{~s}, 1 \mathrm{H}, \mathrm{H}_{A}\right), 4.19\left(\mathrm{~s}, 2 \mathrm{H}, \mathrm{C}_{6} \mathrm{CH}_{2}\right), 2.10(\mathrm{~s}, 3 \mathrm{H}$, $\mathrm{CH}_{3}$ ); Anal.Calcd for $\mathrm{C}_{18} \mathrm{H}_{16} \mathrm{~N}_{2} \mathrm{~S}$ : C 73.97, H 5.48, N 9.59. Found: C 73.94, H 5.68, N 9.60\%

2.1g 4-(2,4-Dichlorophenyl)-1,3,4,5-tetrahydro-2Hindeno $[1,2-d]$ pyrimidine-2-thione (7): IR $(\mathrm{KBr}$, $\left.\mathrm{cm}^{-1}\right) 3434.3(\mathrm{NH}), 1184.0(\mathrm{C}=\mathrm{S}) ;{ }^{1} \mathrm{H}$ NMR $(\delta, \mathrm{ppm})$ : 8.42 (s, 1H, NH), 7.24-7.62 (m, 7H, Ar-H), 6.86 (s, $1 \mathrm{H}, \mathrm{NH}), 6.08\left(\mathrm{~s}, 1 \mathrm{H}, \mathrm{H}_{A}\right), 4.09$ (s, $2 \mathrm{H}, \mathrm{C}_{6} \mathrm{CH}_{2}$ ); Anal. Calcd for $\mathrm{C}_{17} \mathrm{H}_{12} \mathrm{~N}_{2} \mathrm{SCl}_{2}$ : C 58.78, H 3.46, N 8.07. Found: C 58.59, H 3.39, N 7.99\%

2.1h 4-(2-Nitrophenyl)-1,3,4,5-tetrahydro-2H-indeno [1,2-d]pyrimidine-2-thione $(\mathbf{8}): \quad \mathrm{IR} \quad\left(\mathrm{KBr}, \quad \mathrm{cm}^{-1}\right)$ : $3429.3(\mathrm{NH}), 1189.7(\mathrm{C}=\mathrm{S}) ;{ }^{1} \mathrm{H}$ NMR $(\delta, \mathrm{ppm}): 10.80$ (s, 1H, NH), $8.94(\mathrm{~s}, 1 \mathrm{H}, \mathrm{NH}), 7.22-8.75(\mathrm{~m}, 8 \mathrm{H}, \mathrm{Ar}-$ $\mathrm{H}), 5.77\left(\mathrm{~s}, 1 \mathrm{H}, \mathrm{H}_{A}\right), 4.11\left(\mathrm{~s}, 2 \mathrm{H}, \mathrm{C}_{6} \mathrm{CH}_{2}\right)$; Anal.Calcd for $\mathrm{C}_{17} \mathrm{H}_{13} \mathrm{~N}_{3} \mathrm{SO}_{2}$ : C 63.16, H 4.02, N 13.00. Found: $\mathrm{C}$ $63.03, \mathrm{H} 3.95, \mathrm{~N} 12.95 \%$

2.1i 4-Phenyl-1,3,4,5-tetrahydro-2H-indeno[1,2-d] pyrimidine-2-thione (9): $\mathrm{IR}\left(\mathrm{KBr}, \quad \mathrm{cm}^{-1}\right) \quad 3418.0$ $(\mathrm{NH}), 1180.5(\mathrm{C}=\mathrm{S}) ;{ }^{1} \mathrm{H}$ NMR $(\delta, \mathrm{ppm}): 10.18(\mathrm{~s}, 1 \mathrm{H}$, $\mathrm{NH}), 9.11(\mathrm{~s}, 1 \mathrm{H}, \mathrm{NH}), 7.24-8.76(\mathrm{~m}, 9 \mathrm{H}, \mathrm{Ar}-\mathrm{H}), 5.99$ $\left(\mathrm{s}, 1 \mathrm{H}, \mathrm{H}_{A}\right) ; 4.29\left(\mathrm{~s}, 2 \mathrm{H}, \mathrm{C}_{6} \mathrm{CH}_{2}\right)$; Mass $(\mathrm{m} / \mathrm{z}): 278 \mathrm{M}^{+}$, 
219, 114, 77, 59; Anal.Calcd for $\mathrm{C}_{17} \mathrm{H}_{14} \mathrm{~N}_{2} \mathrm{~S}$ : C 73.38, H 5.03, N 10.07. Found: C 73.05, H 4.98, N 10.09\%

2.1j 4-[4-(Dimethylamino)phenyl]-1,3,4,5-tetrahydro -2H-indeno $[1,2-d]$ pyrimidine-2-thione (10): $\mathrm{IR}(\mathrm{KBr}$, $\left.\mathrm{cm}^{-1}\right)$ : $3420.6(\mathrm{NH}), 1190.5(\mathrm{C}=\mathrm{S}) ;{ }^{1} \mathrm{H}$ NMR $(\delta, \mathrm{ppm})$ : $9.91(\mathrm{~s}, 1 \mathrm{H}, \mathrm{NH}), 8.83(\mathrm{~s}, 1 \mathrm{H}, \mathrm{NH}), 7.12-8.25(\mathrm{~m}, 8 \mathrm{H}$, Ar-H), 6.01 (s, $\left.1 \mathrm{H}, \mathrm{H}_{A}\right) ; 4.30$ (s, $\left.2 \mathrm{H}, \mathrm{C}_{6} \mathrm{CH}_{2}\right), 2.34$ (s, $\left.6 \mathrm{H}, \mathrm{N}\left(\mathrm{CH}_{3}\right)_{2}\right)$; Anal.Calcd for $\mathrm{C}_{19} \mathrm{H}_{19} \mathrm{~N}_{3} \mathrm{~S}: \mathrm{C} 71.02, \mathrm{H}$ 5.92, N 13.08. Found: C 71.10, H 5.98, N 13.07\%

\subsection{General procedure for the synthesis of 2-(Ethyl/methylthio)-4-aryl-4,5-dihydro- $1 \mathrm{H}$ - indeno[1,2-d]pyrimidines}

To indeno[1,2- $d$ ]pyrimidine-2-thione $\quad \mathbf{1 - 1 0} \quad(0.004$ mole) dissolved in ethanol, was added $\mathrm{NaOH}$ solution which was prepared by dissolving $\mathrm{NaOH}(0.160 \mathrm{~g})$ in water $(2 \mathrm{~mL})$. The mixture was cooled. To this mixture, diethyl sulphate $(0.004$ mole $)$ or dimethyl sulphate (0.004 mole) was added drop-wise while stirring the reaction mixture continuously. Then the reaction mixture was refluxedfor $3 \mathrm{~h}$. After refluxing, the reaction mixture was cooled and poured over crushed ice. Solid separated was filtered under reduced pressure, dried and recrystallized from ethanol. The spectral data of the prepared compounds are given below:

1a ${ }^{1} H N M R(\delta, p p m): 8.13(\mathrm{~s}, 1 \mathrm{H}, \mathrm{NH}), 7.02-7.64(\mathrm{~m}$, $8 \mathrm{H}, \mathrm{Ar}-\mathrm{H}), 6.96\left(\mathrm{~s}, 1 \mathrm{H}, \mathrm{H}_{A}\right), 4.10\left(\mathrm{~s}, 2 \mathrm{H}, \mathrm{C}_{6} \mathrm{CH}_{2}\right), 3.89$ (s, $\left.3 \mathrm{H}, \mathrm{OCH}_{3}\right), 2.72\left(\mathrm{~s}, 3 \mathrm{H}, \mathrm{S}-\mathrm{CH}_{3}\right) ; \mathrm{m} / \mathrm{z} 322 \mathrm{M}^{+}, 321$, 274, 77; Anal.Calcd for $\mathrm{C}_{19} \mathrm{H}_{18} \mathrm{~N}_{2}$ SO: C 70.80, H 5.59, N 8.69. Found: C 70.72, H 5.28, N 8.60\%

1b ${ }^{1} H$ NMR $(\delta, p p m): 8.14(\mathrm{~s}, 1 \mathrm{H}, \mathrm{NH}), 6.93-7.59$ (m, $8 \mathrm{H}, \mathrm{Ar}-\mathrm{H}), 6.87\left(\mathrm{~s}, 1 \mathrm{H}, \mathrm{H}_{A}\right), 3.94\left(\mathrm{~s}, 2 \mathrm{H}, \mathrm{C}_{6} \mathrm{CH}_{2}\right)$, $3.86\left(\mathrm{~s}, 3 \mathrm{H}, \mathrm{OCH}_{3}\right), 3.70-3.74\left(\mathrm{q}, 1 \mathrm{H}\right.$ of $\left.\mathrm{S}-\mathrm{CH}_{2}\right)$, $3.28-3.33$ (q, $1 \mathrm{H}$ of S- $\mathrm{CH}_{2}$ ), $1.48-1.51$ (t, $3 \mathrm{H}, \mathrm{S}_{-} \mathrm{CH}_{2}-$ $\left.\mathrm{CH}_{3}\right) ; \mathrm{m} / \mathrm{z} 336 \mathrm{M}^{+}, 335,275,249,219$; Anal.Calcd for $\mathrm{C}_{20} \mathrm{H}_{20} \mathrm{~N}_{2} \mathrm{SO}: \mathrm{C} 71.43, \mathrm{H}$ 5.95, N 8.33. Found: C 71.52, H $5.68, \mathrm{~N} 8.30 \%$

2a ${ }^{1} H N M R(\delta, p p m): 9.00-9.01(\mathrm{~s}, 1 \mathrm{H}, \mathrm{NH}), 7.45-8.55$ $(\mathrm{m}, 8 \mathrm{H}, \mathrm{Ar}-\mathrm{H}), 6.89\left(\mathrm{~s}, 1 \mathrm{H}, \mathrm{H}_{A}\right) ; 4.12\left(\mathrm{~s}, 2 \mathrm{H}, \mathrm{C}_{6} \mathrm{CH}_{2}\right)$, 2.75 (s, 3H, S- $\mathrm{CH}_{3}$ ); Anal.Calcd for $\mathrm{C}_{18} \mathrm{H}_{17} \mathrm{~N}_{3} \mathrm{SO}_{2}$ : C 64.09, H 4.51, N 12.46. Found: C 63.99, H 4.58, N $12.52 \%$

2b ${ }^{1} H$ NMR ( $\left.\delta, p p m\right): 9.00(\mathrm{~s}, 1 \mathrm{H}, \mathrm{NH}), 7.45-8.55$ (m, $8 \mathrm{H}, \mathrm{Ar}-\mathrm{H}), 5.75\left(\mathrm{~s}, 1 \mathrm{H}, \mathrm{H}_{A}\right), 4.12\left(\mathrm{~s}, 2 \mathrm{H}, \mathrm{C}_{6} \mathrm{CH}_{2}\right)$, $3.34-3.38$ (q, 2H, S-CH $)_{2}, 1.50-1.53\left(\mathrm{t}, 3 \mathrm{H}, \mathrm{S}_{-} \mathrm{CH}_{2}-\right.$ $\mathrm{CH}_{3}$ ); Anal.Calcd for $\mathrm{C}_{19} \mathrm{H}_{17} \mathrm{~N}_{3} \mathrm{SO}_{2}: \mathrm{C} 64.96, \mathrm{H} 4.84$, $\mathrm{N} 11.96$. Found: C 64.82, H 4.69, N $11.60 \%$

3a ${ }^{1} H$ NMR $(\delta, p p m): 6.88-7.62(\mathrm{~m}, 8 \mathrm{H}, \mathrm{NH} \& \mathrm{Ar}-\mathrm{H})$, $6.04\left(\mathrm{~s}, 2 \mathrm{H}, \mathrm{O}_{-} \mathrm{CH}_{2}-\mathrm{O}\right), 5.92\left(\mathrm{~s}, 1 \mathrm{H}, \mathrm{H}_{A}\right) 3.99(\mathrm{~s}, 2 \mathrm{H}$,
$\mathrm{C}_{6} \mathrm{CH}_{2}$ ), 1.24-1.26 (s, 3H, S- $\mathrm{CH}_{3}$ ); m/z $336 \mathrm{M}^{+}, 335$, 321, 320, 263; Anal.Calcd for $\mathrm{C}_{19} \mathrm{H}_{16} \mathrm{~N}_{2} \mathrm{SO}_{2}$ : C 67.86, $\mathrm{H} 4.76, \mathrm{~N} 8.33$. Found: C 67.43, H 4.52, N 8.21\%

3b ${ }^{1} H$ NMR $(\delta, p p m): 6.87-7.62(\mathrm{~m}, 8 \mathrm{H}, \mathrm{NH} \& \mathrm{Ar}-\mathrm{H})$, $6.04\left(\mathrm{~s}, 2 \mathrm{H}, \mathrm{O}-\mathrm{CH}_{2}-\mathrm{O}\right), 5.92\left(\mathrm{~s}, 1 \mathrm{H}, \mathrm{H}_{\mathrm{A}}\right), 3.98(\mathrm{~s}, 2 \mathrm{H}$, $\left.\mathrm{C}_{6} \mathrm{CH}_{2}\right), 3.70-3.75$ (q, $1 \mathrm{H}$ of S-CH$), 3.11-3.15(\mathrm{q}, 1 \mathrm{H}$ of S-CH $\mathrm{CH}_{2}$ ), 1.48-1.51 (t, 3H, S- $-\mathrm{CH}_{2}-\mathrm{CH}_{3}$ ); Anal.Calcd for $\mathrm{C}_{20} \mathrm{H}_{18} \mathrm{~N}_{2} \mathrm{SO}_{2}$ : C 68.57, H 5.14, N 8.00. Found: C $68.45, \mathrm{H} 5.28, \mathrm{~N} 7.91 \%$

4a ${ }^{1} H$ NMR $(\delta, p p m): 8.18(\mathrm{~s}, 1 \mathrm{H}, \mathrm{NH}), 7.02-8.19(\mathrm{~m}$, $8 \mathrm{H}, \mathrm{Ar}-\mathrm{H} \& \mathrm{OH}), 5.93\left(\mathrm{~s}, 1 \mathrm{H}, \mathrm{H}_{A}\right), 4.14\left(\mathrm{~s}, 2 \mathrm{H}, \mathrm{C}_{6} \mathrm{CH}_{2}\right)$, $3.98\left(\mathrm{~s}, 3 \mathrm{H}, \mathrm{OCH}_{3}\right), 1.90\left(\mathrm{~s}, 3 \mathrm{H}, \mathrm{S}-\mathrm{CH}_{3}\right)$; Anal.Calcd for $\mathrm{C}_{19} \mathrm{H}_{18} \mathrm{~N}_{2} \mathrm{SO}_{2}$ : C 67.45, H 5.32, N 8.28. Found: C 67.36, H 5.58, N 8.16\%

4b ${ }^{1} H$ NMR $(\delta, p p m): 8.17$ (s, 1H, NH), 7.00-8.15 (m, $7 \mathrm{H}, \operatorname{Ar}-\mathrm{H}), 8.01(\mathrm{~s}, 1 \mathrm{H}, \mathrm{OH}), 5.92\left(\mathrm{~s}, 1 \mathrm{H}, \mathrm{H}_{A}\right), 4.14(\mathrm{~s}$, $\left.2 \mathrm{H}, \mathrm{C}_{6} \mathrm{CH}_{2}\right), 3.98\left(\mathrm{~s}, 3 \mathrm{H}, \mathrm{OCH}_{3}\right), 3.69-3.75(\mathrm{q}, 1 \mathrm{H}, \mathrm{S}-$ $\mathrm{CH}_{2}$ ), 3.31-3.35 (q, 1H, S-CH $)_{2}, 0.85-0.88$ (t, 3H, S$\mathrm{CH}_{2}-\mathrm{CH}_{3}$ ); Anal.Calcd for $\mathrm{C}_{20} \mathrm{H}_{20} \mathrm{~N}_{2} \mathrm{SO}_{2}$ : C 68.18, H 5.68, N 7.95. Found: C 68.07, H 5.45, N 7.83\%

5a ${ }^{1} H$ NMR $(\delta, p p m): 9.12(\mathrm{~s}, 1 \mathrm{H}, \mathrm{NH}), 7.36-8.49(\mathrm{~m}$, $8 \mathrm{H}, \mathrm{Ar}-\mathrm{H}), 6.23\left(\mathrm{~s}, 1 \mathrm{H}, \mathrm{H}_{A}\right), 4.23\left(\mathrm{~s}, 2 \mathrm{H}, \mathrm{C}_{6} \mathrm{CH}_{2}\right), 2.55$ (s, $3 \mathrm{H}, \mathrm{S}-\mathrm{CH}_{3}$ ); Anal.Calcd for $\mathrm{C}_{18} \mathrm{H}_{15} \mathrm{~N}_{3} \mathrm{SO}_{2}$ : C 64.09, H 4.51, N 12.46. Found: C 63.96, H 4.40, N 12.50\%

5b ${ }^{1} H$ NMR $(\delta, p p m): 9.05(\mathrm{~s}, 1 \mathrm{H}, \mathrm{NH}), 7.36-8.32$ $(\mathrm{m}, 8 \mathrm{H}, \mathrm{Ar}-\mathrm{H}), 5.67\left(\mathrm{~s}, 1 \mathrm{H}, \mathrm{H}_{A}\right), 4.13\left(\mathrm{~s}, 2 \mathrm{H}, \mathrm{C}_{6} \mathrm{CH}_{2}\right)$, 3.56-3.60 (q, $\left.1 \mathrm{H}, \quad \mathrm{S}-\mathrm{CH}_{2}\right), 3.30-3.34$ (q, $1 \mathrm{H}, \mathrm{S}-$ $\mathrm{CH}_{2}$ ), 1.46-1.49 (t, 3H, S- $\mathrm{CH}_{2}-\mathrm{CH}_{3}$ ); Anal.Calcd for $\mathrm{C}_{19} \mathrm{H}_{17} \mathrm{~N}_{3} \mathrm{SO}_{2}$ : C 64.96, H 4.84, N 11.96. Found: C 64.89, H 4.75, N $11.66 \%$

6a ${ }^{1} H$ NMR $(\delta, p p m): 9.01(\mathrm{~s}, 1 \mathrm{H}, \mathrm{NH}), 7.06-8.26(\mathrm{~m}$, $8 \mathrm{H}, \mathrm{Ar}-\mathrm{H}), 5.46\left(\mathrm{~s}, 1 \mathrm{H}, \mathrm{H}_{A}\right), 4.19\left(\mathrm{~s}, 2 \mathrm{H}, \mathrm{C}_{6} \mathrm{CH}_{2}\right), 2.12$ (s, 6H, 4- $\mathrm{CH}_{3} \& \mathrm{~S}_{-} \mathrm{CH}_{3}$ ); Anal.Calcd for $\mathrm{C}_{19} \mathrm{H}_{18} \mathrm{~N}_{2} \mathrm{~S}: \mathrm{C}$ 74.51, H 5.88, N 9.15. Found: C 74.42, H 5.60, N 8.99\% 6b ${ }^{1} H$ NMR $(\delta, p p m): 9.11(\mathrm{~s}, 1 \mathrm{H}, \mathrm{NH}), 7.10-8.33$ $(\mathrm{m}, 8 \mathrm{H}, \mathrm{Ar}-\mathrm{H}), 5.57\left(\mathrm{~s}, 1 \mathrm{H}, \mathrm{H}_{A}\right), 4.03\left(\mathrm{~s}, 2 \mathrm{H}, \mathrm{C}_{6} \mathrm{CH}_{2}\right)$, 3.60-3.64 (q, $\left.1 \mathrm{H}, \mathrm{S}-\mathrm{CH}_{2}\right), 3.43-3.47\left(\mathrm{q}, 1 \mathrm{H}, \mathrm{S}-\mathrm{CH}_{2}\right)$, $2.11\left(\mathrm{~s}, 3 \mathrm{H}, 4-\mathrm{CH}_{3}\right), 1.22-1.25\left(\mathrm{t}, 3 \mathrm{H}, \mathrm{S}-\mathrm{CH}_{2}-\mathrm{CH}_{3}\right)$; ; Anal.Calcd for $\mathrm{C}_{20} \mathrm{H}_{20} \mathrm{~N}_{2} \mathrm{~S}$ : C 75.00, H 6.25, N 8.75. Found: C 69.89, H 6.18, N 8.67\%

7a ${ }^{1} H$ NMR $(\delta, p p m): 8.89(\mathrm{~s}, 1 \mathrm{H}, \mathrm{NH}), 7.22-7.64(\mathrm{~m}$, $7 \mathrm{H}, \mathrm{Ar}-\mathrm{H}), 6.08\left(\mathrm{~s}, 1 \mathrm{H}, \mathrm{H}_{A}\right), 4.08\left(\mathrm{~s}, 2 \mathrm{H}, \mathrm{C}_{6} \mathrm{CH}_{2}\right), 1.24$ (s, $3 \mathrm{H}, \mathrm{S}-\mathrm{CH}_{3}$ ); Anal.Calcd for $\mathrm{C}_{18} \mathrm{H}_{14} \mathrm{~N}_{2} \mathrm{SCl}_{2}$ : C 59.83, H 3.88, N 7.75. Found: C 59.72, H 3.52, N 7.60\%

7b ${ }^{1} H$ NMR $(\delta, p p m): 8.91$ (s, 1H, NH), 7.21-7.63 (m, $7 \mathrm{H}, \mathrm{Ar}-\mathrm{H}), 6.08\left(\mathrm{~s}, 1 \mathrm{H}, \mathrm{H}_{A}\right), 3.70-3.75\left(\mathrm{q}, 1 \mathrm{H}, \mathrm{S}_{-} \mathrm{CH}_{2}\right)$, $3.32-3.36$ (q, $1 \mathrm{H}, \mathrm{S}-\mathrm{CH}_{2}$ ), 4.11 (s, $2 \mathrm{H}, \mathrm{C}_{6} \mathrm{CH}_{2}$ ), 1.22 1.25 (t, 3H, S- $\mathrm{CH}_{2}-\mathrm{CH}_{3}$ ); Anal.Calcd for $\mathrm{C}_{19} \mathrm{H}_{16} \mathrm{~N}_{2} \mathrm{~S}$ : C 60.80, H 4.26, N 7.47. Found: C 60.69, H 4.28, $\mathrm{N} 7.37 \%$

9b ${ }^{1} H$ NMR ( $\left.\delta, p p m\right): 8.17$ (s, 1H, NH), 7.11-8.15 $(\mathrm{m}, 9 \mathrm{H}, \mathrm{Ar}-\mathrm{H}), 5.30\left(\mathrm{~s}, 1 \mathrm{H}, \mathrm{H}_{A}\right), 4.13\left(\mathrm{~s}, 2 \mathrm{H}, \mathrm{C}_{6} \mathrm{CH}_{2}\right)$, 
3.69-3.72 (q, 1H, S- $\mathrm{CH}_{2}$ ), 3.31-3.35 (q, $1 \mathrm{H}, \mathrm{S}-\mathrm{CH}_{2}$ ), 1.49-1.52 (t, 3H, S-CH ${ }_{2}-\mathrm{CH}_{3}$ ); mass: m/z $305 \mathrm{M}^{+}, 219$, 218, 114, 88, 77; Anal.Calcd for $\mathrm{C}_{19} \mathrm{H}_{18} \mathrm{~N}_{2} \mathrm{~S}$ : C 74.51, H 5.88, N 9.15. Found: C 74.62, H 5.67, N 9.01\%

2.3 General procedure for the synthesis 2-(Butylthio)4-aryl-4,5-dihydro-1H-indeno[1,2-d]pyrimidines

A mixture of indeno[1,2- $d$ ]pyrimidine-2-thione 1-10 (0.004 mole), butylbromide (0.004 mole) and absolute alcohol $(5 \mathrm{~mL})$ was refluxed for $5 \mathrm{~h}$. The product was allowed to separate at room temperature. After a long standing of 24-36 h., the product separated was filtered under reduced pressure and recrystallised from ethanol. The spectral data of the prepared compounds is given below:

1c ${ }^{1} \mathrm{H}$ NMR $(\delta, p p m): 8.19$ (s, 1H, NH), 6.98-8.15 (m, $8 \mathrm{H}, \mathrm{Ar}-\mathrm{H}), 6.96\left(\mathrm{~s}, 1 \mathrm{H}, \mathrm{H}_{A}\right), 4.10\left(\mathrm{~s}, 2 \mathrm{H}, \mathrm{C}_{6} \mathrm{CH}_{2}\right), 3.89$ (s, 3H, $\mathrm{OCH}_{3}$ ), 3.30-3.34 (t, $2 \mathrm{H}, \mathrm{S}-\mathrm{CH}_{2}-\mathrm{CH}_{2}-\mathrm{CH}_{2}-$ $\left.\mathrm{CH}_{3}\right), 1.53-1.58\left(\mathrm{~m}, 4 \mathrm{H}, \mathrm{S}-\mathrm{CH}_{2}-\mathrm{CH}_{2}-\mathrm{CH}_{2}-\mathrm{CH}_{3}\right), 0.97-$ $1.00\left(\mathrm{t}, 3 \mathrm{H}, \mathrm{S}-\mathrm{CH}_{2}-\mathrm{CH}_{2}-\mathrm{CH}_{2}-\mathrm{CH}_{3}\right) ; \mathrm{m} / \mathrm{z} 364 \mathrm{M}^{+}, 363$, 249, 89; Anal.Calcd for $\mathrm{C}_{22} \mathrm{H}_{24} \mathrm{~N}_{2}$ SO: C 72.56, H 6.59, N 7.69. Found: C 72.68, H 6.71, N 7.57

2c ${ }^{1} \mathrm{H}$ NMR $(\delta, p p m): 8.88$ (s, $\left.1 \mathrm{H}, \mathrm{NH}\right), 7.23-8.48$ (m, $8 \mathrm{H}, \mathrm{Ar}-\mathrm{H}), 5.99\left(\mathrm{~s}, 1 \mathrm{H}, \mathrm{H}_{A}\right), 4.08\left(\mathrm{~s}, 2 \mathrm{H}, \mathrm{C}_{6} \mathrm{CH}_{2}\right), 3.25-$ 3.28 (t, $\left.2 \mathrm{H}, \mathrm{S}-\mathrm{CH}_{2}-\mathrm{CH}_{2}-\mathrm{CH}_{2}-\mathrm{CH}_{3}\right), 1.50-1.56(\mathrm{~m}, 4 \mathrm{H}$, S- $\left.\mathrm{CH}_{2}-\mathrm{CH}_{2}-\mathrm{CH}_{2}-\mathrm{CH}_{3}\right), 0.98-1.01\left(\mathrm{t}, 3 \mathrm{H}, \mathrm{S}-\mathrm{CH}_{2}-\mathrm{CH}_{2}-\right.$ $\mathrm{CH}_{2}-\mathrm{CH}_{3}$ ); Anal.Calcd for $\mathrm{C}_{21} \mathrm{H}_{21} \mathrm{~N}_{3} \mathrm{SO}_{2}$ : C $66.49, \mathrm{H}$ 5.54, N 11.08. Found: C 66.32, H 5.38, N 11.15\%

3c ${ }^{1} \mathrm{H}$ NMR $(\delta, \mathrm{ppm}): 6.87-8.14(\mathrm{~m}, 8 \mathrm{H}, \mathrm{NH} \& \mathrm{Ar}-$ $\mathrm{H}), 6.03\left(\mathrm{~s}, 2 \mathrm{H}, \mathrm{O}-\mathrm{CH}_{2}-\mathrm{O}\right), 5.98\left(\mathrm{~s}, 1 \mathrm{H}, \mathrm{H}_{A}\right), 3.98$ (s, $2 \mathrm{H}, \mathrm{C}_{6} \mathrm{CH}_{2}$ ), 3.29-3.32 (t, $2 \mathrm{H}, \mathrm{S}-\mathrm{CH}_{2}-\mathrm{CH}_{2}-\mathrm{CH}_{2}-$ $\left.\mathrm{CH}_{3}\right), 1.81-1.85\left(\mathrm{~m}, 2 \mathrm{H}, \mathrm{S}-\mathrm{CH}_{2}-\mathrm{CH}_{2}-\mathrm{CH}_{2}-\mathrm{CH}_{3}\right), 1.52-$ $1.58\left(\mathrm{~m}, 2 \mathrm{H}, \mathrm{S}-\mathrm{CH}_{2}-\mathrm{CH}_{2}-\mathrm{CH}_{2}-\mathrm{CH}_{3}\right), 0.97-1.00(\mathrm{t}, 3 \mathrm{H}$, S- $\mathrm{CH}_{2}-\mathrm{CH}_{2}-\mathrm{CH}_{2}-\mathrm{CH}_{3}$ ); Anal.Calcd for $\mathrm{C}_{22} \mathrm{H}_{22} \mathrm{~N}_{2} \mathrm{SO}_{2}$ : C 69.84, H 5.82, N 7.41. Found: C 69.72, H 5.67, $\mathrm{N} 7.52 \%$

4c ${ }^{1} \mathrm{H}$ NMR ( $\left.\delta, \mathrm{ppm}\right): 8.68$ (s, $\left.1 \mathrm{H}, \mathrm{NH}\right), 7.12-8.25$ $(\mathrm{m}, 8 \mathrm{H}$, Ar- $\mathrm{H} \& \mathrm{OH}), 5.98\left(\mathrm{~s}, 1 \mathrm{H}, \mathrm{H}_{A}\right), 4.21(\mathrm{~s}, 2 \mathrm{H}$, $\left.\mathrm{C}_{6} \mathrm{CH}_{2}\right), 3.97\left(\mathrm{~s}, 3 \mathrm{H}, \mathrm{OCH}_{3}\right), 3.39-3.45(\mathrm{~m}, 1 \mathrm{H}$ of S$\mathrm{CH}_{2}-\mathrm{CH}_{2}-\mathrm{CH}_{2}-\mathrm{CH}_{3}$ ), 3.30-3.34 (m, $1 \mathrm{H}, \mathrm{S}-\mathrm{CH}_{2}-\mathrm{CH}_{2}-$ $\mathrm{CH}_{2}-\mathrm{CH}_{3}$ ), $1.49-1.56$ (m, $4 \mathrm{H}, \mathrm{S}-\mathrm{CH}_{2}-\mathrm{CH}_{2}-\mathrm{CH}_{2}-\mathrm{CH}_{3}$ ), 0.94-0.97 (t, $3 \mathrm{H}, \mathrm{S}-\mathrm{CH}_{2}-\mathrm{CH}_{2}-\mathrm{CH}_{2}-\mathrm{CH}_{3}$ ); Anal.Calcd for $\mathrm{C}_{22} \mathrm{H}_{24} \mathrm{~N}_{2} \mathrm{SO}_{2}$ : C 69.47, $\mathrm{H}$ 6.31, N 7.34. Found: $\mathrm{C}$ $69.59, \mathrm{H} 6.56, \mathrm{~N} 7.28 \%$

5c ${ }^{1} \mathrm{H}$ NMR $(\delta, p p m): 9.21(\mathrm{~s}, 1 \mathrm{H}, \mathrm{NH}), 7.35-8.36(\mathrm{~m}$, $8 \mathrm{H}, \mathrm{Ar}-\mathrm{H}), 6.02\left(\mathrm{~s}, 1 \mathrm{H}, \mathrm{H}_{A}\right), 4.09$ (s, $\left.2 \mathrm{H}, \mathrm{C}_{6} \mathrm{CH}_{2}\right), 3.35-$ $3.40\left(\mathrm{~m}, 1 \mathrm{H}\right.$ of S- $\left.\mathrm{CH}_{2}-\mathrm{CH}_{2}-\mathrm{CH}_{2}-\mathrm{CH}_{3}\right), 3.28-3.31(\mathrm{~m}$, $1 \mathrm{H}$ of S- $\left.\mathrm{CH}_{2}-\mathrm{CH}_{2}-\mathrm{CH}_{2}-\mathrm{CH}_{3}\right), 1.51-1.56(\mathrm{~m}, 4 \mathrm{H}$ of S$\left.\mathrm{CH}_{2}-\mathrm{CH}_{2}-\mathrm{CH}_{2}-\mathrm{CH}_{3}\right), 0.97-1.00$ (t, $3 \mathrm{H}, \mathrm{S}-\mathrm{CH}_{2}-\mathrm{CH}_{2}-$ $\mathrm{CH}_{2}-\mathrm{CH}_{3}$ ); Anal.Calcd for $\mathrm{C}_{21} \mathrm{H}_{21} \mathrm{~N}_{3} \mathrm{SO}_{2}: \mathrm{C} 66.49, \mathrm{H}$ 5.54, N 11.08. Found: C 66.41, H 5.35, N 11.00\% 6c ${ }^{1} \mathrm{H}$ NMR $(\delta, p p m): 8.89(\mathrm{~s}, 1 \mathrm{H}, \mathrm{NH}), 7.10-8.45(\mathrm{~m}$, $8 \mathrm{H}, \mathrm{Ar}-\mathrm{H}), 5.68\left(\mathrm{~s}, 1 \mathrm{H}, \mathrm{H}_{A}\right), 4.02\left(\mathrm{~s}, 2 \mathrm{H}, \mathrm{C}_{6} \mathrm{CH}_{2}\right), 3.35-$ $3.39\left(\mathrm{~m}, 1 \mathrm{H}, \mathrm{S}-\mathrm{CH}_{2}-\mathrm{CH}_{2}-\mathrm{CH}_{2}-\mathrm{CH}_{3}\right), 3.20-3.31(\mathrm{~m}$, $\left.1 \mathrm{H}, \mathrm{S}-\mathrm{CH}_{2}-\mathrm{CH}_{2}-\mathrm{CH}_{2}-\mathrm{CH}_{3}\right), 2.09$ (s, 3H, 4- $\left.\mathrm{CH}_{3}\right), 1.51-$ $1.56\left(\mathrm{~m}, 4 \mathrm{H}, \mathrm{S}-\mathrm{CH}_{2}-\mathrm{CH}_{2}-\mathrm{CH}_{2}-\mathrm{CH}_{3}\right), 0.98-1.01(\mathrm{t}, 3 \mathrm{H}$, S- $\mathrm{CH}_{2}-\mathrm{CH}_{2}-\mathrm{CH}_{2}-\mathrm{CH}_{3}$ ); Anal.Calcd for $\mathrm{C}_{22} \mathrm{H}_{24} \mathrm{~N}_{2} \mathrm{~S}$ : C 75.86, H 6.89, N 8.04. Found: C 75.71, H 6.72, N $7.97 \%$

8c ${ }^{1} \mathrm{H}$ NMR ( $\delta$,ppm): 9.19 (s, $\left.1 \mathrm{H}, \mathrm{NH}\right), 7.23-8.45(\mathrm{~m}$, $8 \mathrm{H}, \mathrm{Ar}-\mathrm{H}), 6.12\left(\mathrm{~s}, 1 \mathrm{H}, \mathrm{H}_{A}\right), 4.09\left(\mathrm{~s}, 2 \mathrm{H}, \mathrm{C}_{6} \mathrm{CH}_{2}\right), 3.29$ $3.34\left(\mathrm{~m}, 1 \mathrm{H}\right.$ of S- $\left.\mathrm{CH}_{2}-\mathrm{CH}_{2}-\mathrm{CH}_{2}-\mathrm{CH}_{3}\right), 3.19-3.21(\mathrm{~m}$, $1 \mathrm{H}$ of S- $\left.\mathrm{CH}_{2}-\mathrm{CH}_{2}-\mathrm{CH}_{2}-\mathrm{CH}_{3}\right), 1.48-1.57$ (m, $4 \mathrm{H}$ of S$\mathrm{CH}_{2}-\mathrm{CH}_{2}-\mathrm{CH}_{2}-\mathrm{CH}_{3}$ ), $0.86-0.89$ (t, $3 \mathrm{H}, \mathrm{S}-\mathrm{CH}_{2}-\mathrm{CH}_{2}-$ $\mathrm{CH}_{2}-\mathrm{CH}_{3}$ ); Anal.Calcd for $\mathrm{C}_{21} \mathrm{H}_{21} \mathrm{~N}_{3} \mathrm{SO}_{2}: \mathrm{C} 66.49, \mathrm{H}$ 5.54, N 11.08. Found: C 66.39, H 5.62, N 11.01\%

9c ${ }^{1} \mathrm{H}$ NMR $(\delta, p p m): 12.12(\mathrm{~s}, 1 \mathrm{H}, \mathrm{NH}), 7.16-8.33$ (m, $9 \mathrm{H}, \mathrm{Ar}-\mathrm{H}), 6.03\left(\mathrm{~s}, 1 \mathrm{H}, \mathrm{H}_{A}\right), 4.33\left(\mathrm{~s}, 2 \mathrm{H}, \mathrm{C}_{6} \mathrm{CH}_{2}\right), 3.40$ $3.43\left(\mathrm{t}, 2 \mathrm{H}, \mathrm{S}-\mathrm{CH}_{2}-\mathrm{CH}_{2}-\mathrm{CH}_{2}-\mathrm{CH}_{3}\right), 1.53-1.65(\mathrm{~m}, 4 \mathrm{H}$, $\left.\mathrm{S}-\mathrm{CH}_{2}-\mathrm{CH}_{2}-\mathrm{CH}_{2}-\mathrm{CH}_{3}\right), 0.66-0.70\left(\mathrm{t}, 3 \mathrm{H}, \mathrm{S}-\mathrm{CH}_{2}-\mathrm{CH}_{2}-\right.$ $\mathrm{CH}_{2}-\mathrm{CH}_{3}$ ); Anal.Calcd for $\mathrm{C}_{21} \mathrm{H}_{22} \mathrm{~N}_{2} \mathrm{~S}: \mathrm{C} 75.45, \mathrm{H}$ 6.58 , N 8.38. Found: C 75.33, H 6.32, N 8.29\%

\subsection{General procedure for the synthesis}

2-(Benzylthio)-4-aryl-4,5-dihydro-1H-indeno[1,2d]pyrimidines

To indeno[1,2- $d$ ]pyrimidine-2-thione $\quad \mathbf{1 - 1 0} \quad(0.004$ mole) dissolved in alcohol $(5 \mathrm{~mL})$ was added benzyl chloride $(0.004$ mole) and the reaction mixture was refluxed for $5 \mathrm{~h}$. The mixture was cooled at room temperature. The solid separated was filtered and recrystallised from ethanol. The spectral data of the prepared compounds is given below.

1d ${ }^{1} \mathrm{H}$ NMR $(\delta, \mathrm{ppm}): 8.12$ (s, 1H, NH), 6.98-7.63 (m, $13 \mathrm{H}, \mathrm{Ar}-\mathrm{H}), 6.96\left(\mathrm{~s}, 1 \mathrm{H}, \mathrm{H}_{A}\right), 4.60-4.63(\mathrm{~d}, 1 \mathrm{H}$ of S$\mathrm{CH}_{2}-\mathrm{C}_{6} \mathrm{H}_{5}$ ); 4.12-4.14 (d, $1 \mathrm{H}$ of S- $\mathrm{CH}_{2}-\mathrm{C}_{6} \mathrm{H}_{5}$ ), 4.01(s, $\left.2 \mathrm{H}, \mathrm{C}_{6} \mathrm{CH}_{2}\right), 3.86\left(\mathrm{~s}, 3 \mathrm{H}, \mathrm{OCH}_{3}\right) ; \mathrm{m} / \mathrm{z} 398 \mathrm{M}^{+}, 396$, 275, 273, 249; Anal.Calcd for $\mathrm{C}_{25} \mathrm{H}_{22} \mathrm{~N}_{2} \mathrm{SO}: \mathrm{C} 75.37$, H 5.53, N 7.03. Found: C 75.28, H 5.42, N 7.13\%

2d ${ }^{1} \mathrm{H}$ NMR $(\delta, \mathrm{ppm}): 8.96(\mathrm{~s}, 1 \mathrm{H}, \mathrm{NH}), 7.10-8.51(\mathrm{~m}$, $13 \mathrm{H}, \mathrm{Ar}-\mathrm{H}), 6.13\left(\mathrm{~s}, 1 \mathrm{H}, \mathrm{H}_{A}\right), 5.02-5.03(\mathrm{~d}, J=4.0 \mathrm{~Hz}$, $1 \mathrm{H}$ of $\left.\mathrm{S}-\mathrm{CH}_{2}-\mathrm{C}_{6} \mathrm{H}_{5}\right), 4.98-4.99(\mathrm{~d}, J=4.0 \mathrm{~Hz}, 1 \mathrm{H}$ of S- $\left.\mathrm{CH}_{2}-\mathrm{C}_{6} \mathrm{H}_{5}\right), 4.15$ (s, $2 \mathrm{H}, \mathrm{C}_{6} \mathrm{CH}_{2}$ ); Anal.Calcd for $\mathrm{C}_{24} \mathrm{H}_{19} \mathrm{~N}_{3} \mathrm{SO}_{2}$ : C 69.73, H 4.60, N 10.17. Found: C $69.62, \mathrm{H} 4.78, \mathrm{~N} 10.06 \%$

3d ${ }^{1} \mathrm{H}$ NMR $(\delta, p p m): 6.87-7.64(\mathrm{~m}, 13 \mathrm{H}, \mathrm{NH} \& \mathrm{Ar}-$ $\mathrm{H}), 6.02\left(\mathrm{~s}, 2 \mathrm{H}, \mathrm{O}-\mathrm{CH}_{2}-\mathrm{O}\right), 5.93\left(\mathrm{~s}, 1 \mathrm{H}, \mathrm{H}_{A}\right), 3.97(\mathrm{~s}$, $\left.2 \mathrm{H}, \mathrm{C}_{6} \mathrm{CH}_{2}\right), 4.58-4.60$ (d, $1 \mathrm{H}$ of S- $\left.\mathrm{CH}_{2}-\mathrm{C}_{6} \mathrm{H}_{5}\right), 4.06-$ $4.09\left(\mathrm{~d}, 1 \mathrm{H}\right.$ of $\left.\mathrm{S}-\mathrm{CH}_{2}-\mathrm{C}_{6} \mathrm{H}_{5}\right), 3.97\left(\mathrm{~s}, 2 \mathrm{H}, \mathrm{C}_{6} \mathrm{CH}_{2}\right)$; Anal.Calcd for $\mathrm{C}_{25} \mathrm{H}_{20} \mathrm{~N}_{2} \mathrm{SO}_{2}$ : C 72.81, H 4.85, N 6.79. Found: C 72.90, H 5.13, N 6.60\% 
Table 1. Synthesis of 4-aryl-1,3,4,5-tetrahydro-2H-indeno[1,2- $d]$ pyrimidine-2-thiones (1-10).

\begin{tabular}{|c|c|c|c|c|c|c|}
\hline \multirow[t]{2}{*}{ Product } & \multirow[t]{2}{*}{$\mathrm{R}$} & \multicolumn{2}{|c|}{ Reaction time } & \multicolumn{2}{|c|}{$\%$ Yield } & \multirow[t]{2}{*}{$\mathrm{mp}\left({ }^{\circ} \mathrm{C}\right)$} \\
\hline & & $\begin{array}{l}\text { Microwave } \\
\text { time (min) }\end{array}$ & $\begin{array}{c}\text { Reflux } \\
\text { time (hrs) }\end{array}$ & Microwave & Reflux & \\
\hline 1 & $4-\mathrm{OCH}_{3}$ & 8.00 & 5.30 & 48 & 43 & $188-190$ \\
\hline 2 & $3-\mathrm{NO}_{2}$ & 4.30 & 5.00 & 92 & 72 & $224-226$ \\
\hline 3 & $2,3-\left(\mathrm{O}-\mathrm{CH}_{2}-\mathrm{O}\right)$ & 5.30 & 4.30 & 75 & 30 & $186-188$ \\
\hline 4 & $4-\mathrm{OH}, 3-\mathrm{OCH}_{3}$ & 5.00 & 5.00 & 67 & 48 & $184-185$ \\
\hline 5 & $4-\mathrm{NO}_{2}$ & 3.00 & 5.30 & 39 & 33 & $245-247$ \\
\hline 6 & $2-\mathrm{CH}_{3}$ & 4.00 & 5.00 & 46 & 40 & $212-214$ \\
\hline 7 & $2,4-(\mathrm{Cl})$ & 5.30 & 5.30 & 41 & 38 & 219-221 \\
\hline 8 & $2-\mathrm{NO}_{2}$ & 2.30 & 5.00 & 18 & 16 & $159-161$ \\
\hline 9 & $\mathrm{H}$ & 4.30 & 4.30 & 52 & 27 & 219-221 \\
\hline 10 & $4-\mathrm{N}\left(\mathrm{CH}_{3}\right)_{2}$ & 5.00 & 5.00 & 40 & 34 & $171-172$ \\
\hline
\end{tabular}

4d ${ }^{1} \mathrm{H}$ NMR $(\delta, p p m): 8.72(\mathrm{~s}, 1 \mathrm{H}, \mathrm{NH}), 7.08-8.39(\mathrm{~m}$, $13 \mathrm{H}, \mathrm{Ar}-\mathrm{H} \& \mathrm{OH}), 6.01\left(\mathrm{~s}, 1 \mathrm{H}, \mathrm{H}_{A}\right), 4.53-4.55(\mathrm{~d}, 1 \mathrm{H}$ of S- $\left.\mathrm{CH}_{2}-\mathrm{C}_{6} \mathrm{H}_{5}\right), 4.39-4.42\left(\mathrm{~d}, 1 \mathrm{H}\right.$ of S- $\mathrm{CH}_{2}-\mathrm{C}_{6} \mathrm{H}_{5}$ ), $4.18\left(\mathrm{~s}, 2 \mathrm{H}, \mathrm{C}_{6} \mathrm{CH}_{2}\right), 3.96\left(\mathrm{~s}, 3 \mathrm{H}, \mathrm{OCH}_{3}\right)$; Anal.Calcd for $\mathrm{C}_{25} \mathrm{H}_{22} \mathrm{~N}_{2} \mathrm{SO}_{2}$ : C 72.46, H 5.31, N 6.76. Found: C $72.39, \mathrm{H} 5.22, \mathrm{~N} 6.65 \%$

5d ${ }^{1} \mathrm{H}$ NMR $(\delta, p p m): 8.99$ (s, $\left.1 \mathrm{H}, \mathrm{NH}\right), 7.11-8.48$ $(\mathrm{m}, 13 \mathrm{H}, \operatorname{Ar}-\mathrm{H}), 6.05\left(\mathrm{~s}, 1 \mathrm{H}, \mathrm{H}_{A}\right), 5.00-5.03(\mathrm{~d}, 1 \mathrm{H}$ of S- $\left.\mathrm{CH}_{2}-\mathrm{C}_{6} \mathrm{H}_{5}\right), 4.85-4.88$ (d, $1 \mathrm{H}$ of S- $\mathrm{CH}_{2}-\mathrm{C}_{6} \mathrm{H}_{5}$ ), $4.13\left(\mathrm{~s}, 2 \mathrm{H}, \mathrm{C}_{6} \mathrm{CH}_{2}\right)$,) Anal.Calcd for $\mathrm{C}_{24} \mathrm{H}_{19} \mathrm{~N}_{3} \mathrm{SO}_{2}$ : C 69.73, H 4.60, N 10.17. Found: C 69.82, H 4.51, N $10.06 \%$

8d ${ }^{1} \mathrm{H}$ NMR ( $\delta$,ppm): $9.02(\mathrm{~s}, 1 \mathrm{H}, \mathrm{NH}), 7.24-8.67(\mathrm{~m}$, $13 \mathrm{H}, \mathrm{Ar}-\mathrm{H}), 5.99\left(\mathrm{~s}, 1 \mathrm{H}, \mathrm{H}_{A}\right), 5.24-5.27(\mathrm{~d}, 1 \mathrm{H}$ of S$\left.\mathrm{CH}_{2}-\mathrm{C}_{6} \mathrm{H}_{5}\right), 4.65-4.67$ (d, $1 \mathrm{H}$ of S- $\left.\mathrm{CH}_{2}-\mathrm{C}_{6} \mathrm{H}_{5}\right), 4.21$ (s, $2 \mathrm{H}, \mathrm{C}_{6} \mathrm{CH}_{2}$ ); Anal.Calcd for $\mathrm{C}_{24} \mathrm{H}_{19} \mathrm{~N}_{3} \mathrm{SO}_{2}$ : C 69.73, $\mathrm{H}$ 4.60, N 10.17. Found: C 69.69, H 4.69, N 10.10\%

9d ${ }^{1} \mathrm{H}$ NMR ( $\left.\delta, \mathrm{ppm}\right): 9.23$ (s, 1H, NH), 7.86-8.67 (m, $14 \mathrm{H}, \mathrm{Ar}-\mathrm{H}), 6.06\left(\mathrm{~s}, 1 \mathrm{H}, \mathrm{H}_{A}\right), 5.11-5.13(\mathrm{~d}, 1 \mathrm{H}$ of S$\mathrm{CH}_{2}-\mathrm{C}_{6} \mathrm{H}_{5}$ ), 4.45-4.48 (d, $1 \mathrm{H}$ of S- $\left.\mathrm{CH}_{2}-\mathrm{C}_{6} \mathrm{H}_{5}\right), 4.22$ (s, $2 \mathrm{H}, \mathrm{C}_{6} \mathrm{CH}_{2}$ ); Anal.Calcd for $\mathrm{C}_{24} \mathrm{H}_{20} \mathrm{~N}_{2} \mathrm{~S}: \mathrm{C} 78.26, \mathrm{H}$ 5.43, N 7.61. Found: C 78.33, H 5.27, N 7.58\% 10d ${ }^{1} \mathrm{H}$ NMR $(\delta$, ppm): 8.92 (s, 1H, NH), 7.14-8.45 $(\mathrm{m}, 13 \mathrm{H}, \mathrm{Ar}-\mathrm{H}), 6.05\left(\mathrm{~s}, 1 \mathrm{H}, \mathrm{H}_{A}\right), 5.26-5.29(\mathrm{~d}, 1 \mathrm{H}$ of S- $\mathrm{CH}_{2}-\mathrm{C}_{6} \mathrm{H}_{5}$ ), 4.43-4.46 (d, $1 \mathrm{H}$ of S- $\left.\mathrm{CH}_{2}-\mathrm{C}_{6} \mathrm{H}_{5}\right), 4.21$ (s, $2 \mathrm{H}, \mathrm{C}_{6} \mathrm{CH}_{2}$ ), 2.31 (s, $\left.6 \mathrm{H}, \mathrm{N}\left(\mathrm{CH}_{3}\right)_{2}\right)$; Anal.Calcd for $\mathrm{C}_{26} \mathrm{H}_{25} \mathrm{~N}_{3} \mathrm{~S}: \mathrm{C} 75.91, \mathrm{H}$ 6.08, N 10.22. Found: C 75.79, H 5.95, N $10.01 \%$

\section{Results and discussions}

\subsection{Chemistry}

The one-pot multicomponent reactions have received considerable attention as it leads to rate enhancement, higher yields, reduction in time, money and energy. Thus, in order to meet the fundamental scientific challenges of protecting the human health and environment and also simultaneously achieving commercial viability, the synthesis of indeno[1,2- $d$ ]pyrimidine-2thiones were carried out through one-pot multicomponent condensation reactions under microwave irradiations. For comparison, these reactions were also carried

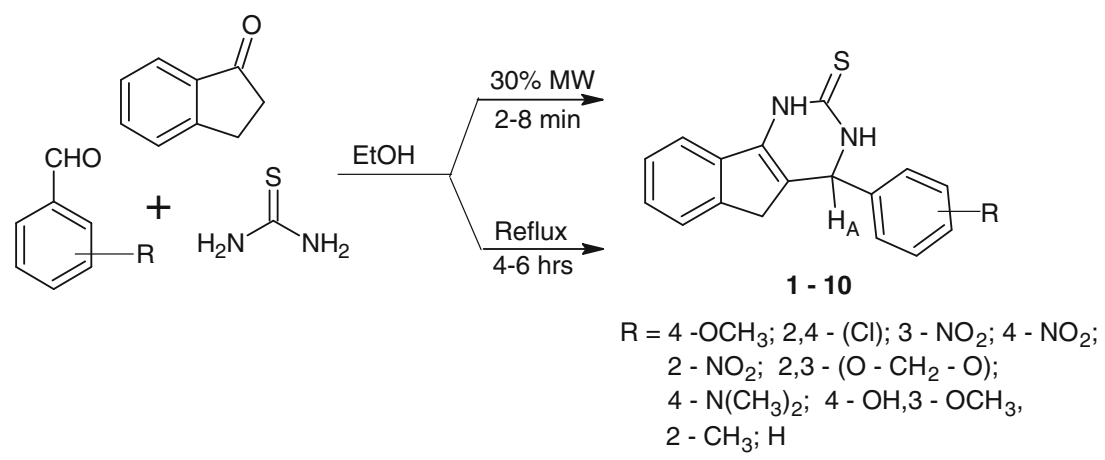

Scheme 1. Synthesis of indeno[1,2- $d]$ pyrimidine-2-thiones. 


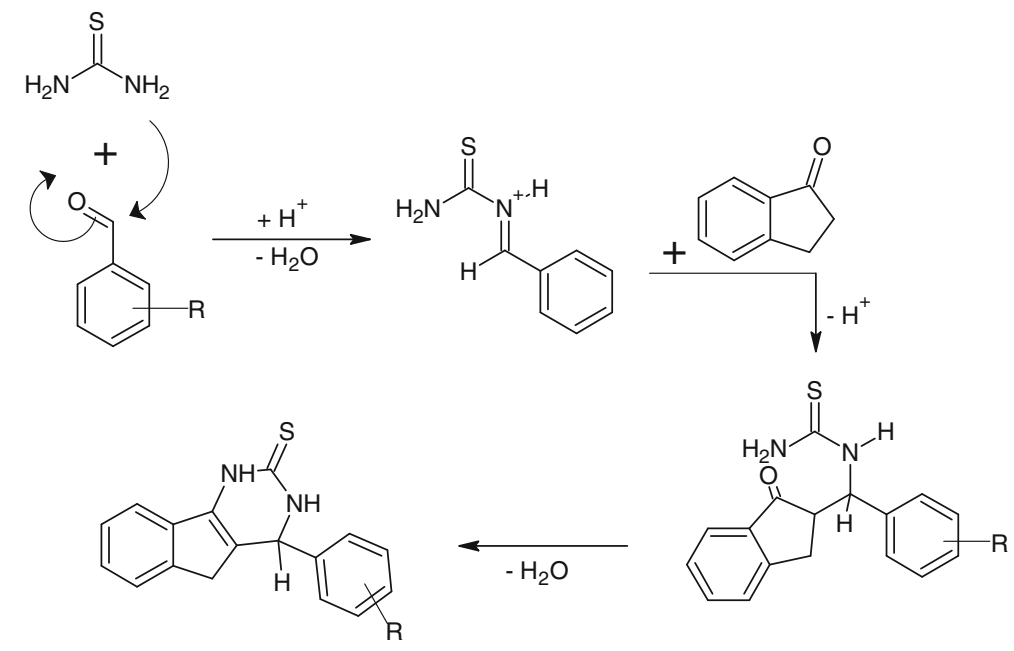

Scheme 2. Mechanism for the synthesis of indeno[1,2-d] pyrimidine-2-thiones.

out through thermal conditions (table 1). For the reactions, the equimolar mixture of 1-indanone, thiourea and substituted aldehydes were irradiated in microwave for 2-8 min. using 3-4 drops of conc. $\mathrm{HCl}$ and absolute alcohol as solvent (scheme 1).

Literature study ${ }^{6,17}$ shows that, earlier the mechanism of the classical three-component Biginelli condensation has not been elucidated with certainty. But now, it has been established that the first step in Biginelli reaction involves the acid catalysed formation of an $\mathrm{N}$ acyliminium ion intermediate from aldehyde and urea component. Then, the interception of iminium ion by ethyl acetoacetate form DHPM. Thus, working on the same guidelines, the proposed mechanism for the above mentioned reaction is given in scheme 2 .

The indeno[1,2- $d]$ pyrimidine-2-thiones were then alkylated/aralkylated by refluxing a mixture of pyrimidine-2-thiones with alkylating/aralkylating reagents for
3-5 h. taking ethanol as solvent. The completion of the reaction was monitored by TLC and work-up of the reaction yielded compounds which were labelled as 2-(substituted thio)-4-aryl-4,5-dihydro- $1 H$-indeno[1,2$d$ ]pyrimidine (scheme 3 ).

The ultraviolet spectra of S-butyl, S-ethyl, S-methyl and S-benzyl did not show any bathochromic shift which would have been possible if the two double bonds in pyrimidine ring got conjugated in the preparation of these derivatives. Thus, the structure of the thione derivatives, suggested, for two double bonds is shown in the scheme 3. Also, the mass spectral data unfolded the structure of the compound formed in the reaction mixture. For e.g., the $\mathrm{M}^{+}$peaks and also the peaks observed at m/z 308 (1), 274 (1a), 249 (1) $), 89$ (1c) and 249 (1d) indicate that methyl, ethyl, butyl and benzyl group respectively have been incorporated in the product.

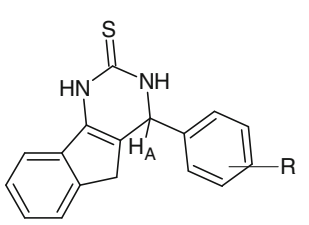

1-10

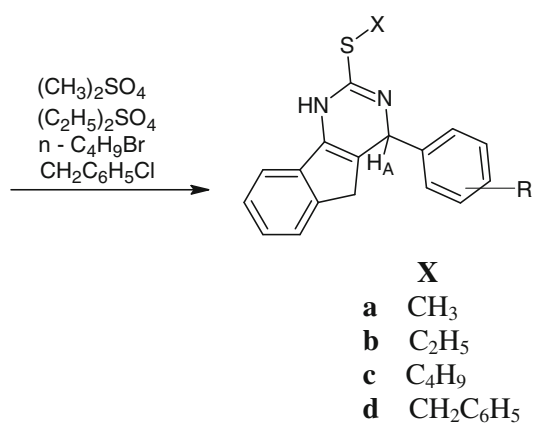

Scheme 3. Synthesis of 2-(substituted thio)-4-aryl-4,5-dihydro-1 $H$-indeno[1,2-d]pyrimidine. 


\subsection{Antibacterial activity}

3.2a Microbal strains: The microorganisms strains used in the agar well diffusion method were supplied by the Institute of Microbial Technology, Chandigarh, India. Gram-positive bacteria: Bacillus subtilis (MTCC 2451), Staphylococcus aureus (MTCC 1740), Staphylococcus epidermidis (MTCC 435), Gram-negative

Table 2. Antimicrobial screening of different compounds against different strains.

\begin{tabular}{|c|c|c|c|c|c|c|c|c|}
\hline \multirow{2}{*}{$\begin{array}{l}\text { Sample } \\
\text { No. }\end{array}$} & \multirow{2}{*}{$\begin{array}{l}\text { Conc. } \\
\mu \mathrm{g} / \text { well }\end{array}$} & \multicolumn{7}{|c|}{ Zone of inhibition (mm) } \\
\hline & & P.fluorescence & S.typhimurium & S. aureus & E.coli & B. subtilis & S.epidermidis & A.calcoaceticus \\
\hline \multirow[t]{2}{*}{ 1a } & 500 & - & - & - & - & - & - & 12 \\
\hline & 250 & - & - & - & - & - & - & 5.4 \\
\hline \multirow[t]{2}{*}{ 1b } & 500 & 10 & - & 14 & - & 20 & - & - \\
\hline & 250 & 4.6 & - & 8.2 & - & 9.8 & - & - \\
\hline \multirow[t]{2}{*}{ 1c } & 500 & - & - & - & - & - & - & - \\
\hline & 250 & - & - & - & - & - & - & - \\
\hline \multirow[t]{2}{*}{$2 \mathbf{a}$} & 500 & - & - & 10 & - & - & - & 05 \\
\hline & 250 & - & - & 5.9 & - & - & - & 2.1 \\
\hline \multirow[t]{2}{*}{$2 b$} & 500 & 12 & 06 & - & - & - & - & - \\
\hline & 250 & 6.7 & 2.9 & - & - & - & - & - \\
\hline \multirow[t]{2}{*}{$2 c$} & 500 & 59 & - & - & - & - & - & - \\
\hline & 250 & 26.2 & - & - & - & - & - & - \\
\hline \multirow[t]{2}{*}{$2 d$} & 500 & - & - & - & - & - & - & - \\
\hline & 250 & - & - & - & - & - & - & - \\
\hline \multirow[t]{2}{*}{$3 a$} & 500 & 12 & - & - & - & - & - & - \\
\hline & 250 & 6.4 & - & - & - & - & - & - \\
\hline \multirow[t]{2}{*}{$3 b$} & 500 & - & - & - & - & - & 07 & - \\
\hline & 250 & - & - & - & - & - & 3.1 & - \\
\hline \multirow[t]{2}{*}{$3 c$} & 500 & - & 15 & - & - & - & - & - \\
\hline & 250 & - & 6.9 & - & - & - & - & - \\
\hline \multirow[t]{2}{*}{$3 d$} & 500 & - & - & - & - & - & - & - \\
\hline & 250 & - & - & - & - & - & - & - \\
\hline \multirow[t]{2}{*}{$4 a$} & 500 & - & 15 & 08 & 19 & 17 & 26 & - \\
\hline & 250 & - & 7.0 & 3.9 & 7.5 & 8.2 & 14 & - \\
\hline \multirow[t]{2}{*}{$4 b$} & 500 & 18 & 21 & 17 & 12 & 13 & 22 & 14 \\
\hline & 250 & 8.3 & 9.0 & 8.8 & 5.8 & 6.1 & 10.3 & 7.3 \\
\hline \multirow[t]{2}{*}{$5 a$} & 500 & - & 05 & - & - & - & 12 & - \\
\hline & 250 & - & 2.2 & - & - & - & 6.3 & - \\
\hline \multirow[t]{2}{*}{$5 d$} & 500 & - & - & - & - & - & - & - \\
\hline & 250 & - & - & - & - & - & - & - \\
\hline \multirow[t]{2}{*}{$6 a$} & 500 & - & - & - & - & - & - & - \\
\hline & 250 & - & - & - & - & - & - & - \\
\hline \multirow[t]{2}{*}{$6 b$} & 500 & - & - & - & - & - & - & - \\
\hline & 250 & - & - & - & - & - & - & - \\
\hline \multirow[t]{2}{*}{$7 a$} & 500 & - & - & 13 & - & - & - & - \\
\hline & 250 & - & - & 5.9 & - & - & - & - \\
\hline $7 b$ & 500 & 13 & 08 & - & - & - & 03 & - \\
\hline & 250 & 6.6 & 3.8 & - & - & - & 1.8 & - \\
\hline 9 & 500 & - & - & - & - & - & - & - \\
\hline & 250 & - & - & - & - & - & - & - \\
\hline $9 b$ & 500 & - & 12 & 09 & 03 & 07 & 10 & - \\
\hline & 250 & - & 5.7 & 4.6 & 1.0 & 3.2 & 4.8 & - \\
\hline 9d & 500 & - & - & - & - & - & - & - \\
\hline & 250 & - & - & - & - & - & - & - \\
\hline Amoxicillin & $5 \mathrm{mg} / \mathrm{ml}$ & 30 & 16 & 29 & 36 & 32 & 25 & 29 \\
\hline Ciprofloxacin & $2.5 \mathrm{mg} / \mathrm{ml}$ & 48 & 29 & 31 & 41 & 40 & 42 & 36 \\
\hline
\end{tabular}

(-): Showing no activity 
bacteria: Escherichia coli (MTCC 443),Salmonella typhimurium (MTCC 1251), Pseudomonas fluorescence (MTCC 103), Acenetobactor calcoaceticus (MTCC 127).

3.2b Anti-microbal screening: In vitro antibacterial activity of the different compounds was studied against seven bacterial strains by the agar well diffusion method as described by Perez et al. $1990^{19}$ with certain modifications. Nutrient agar (Hi Media, India) was used as the bacteriological medium. The antibacterial activity of different compounds was taken at different concentrations (500 and 250/ $\mu \mathrm{g} / \mathrm{well}$ ). The nutrient agar was melted and cooled to $48-50^{\circ} \mathrm{C}$ and a standardized inoculum of $1 \times 10^{6} \mathrm{CFU} / \mathrm{ml}, 0.5 \mathrm{McF}$ arland) was then added aseptically to the molten agar and poured into sterile Petri dishes to give a solid plate. Wells were prepared in the seeded agar plates. The test compound was introduced in the well $(8.5 \mathrm{~mm})$. The plates were incubated overnight at $37^{\circ} \mathrm{C}$. The antimicrobial spectrum of the compounds was determined for the bacterial species in terms of zone sizes around each well. The diameters of zone of inhibition produced by the agent were compared with those produced by the commercial control antibiotics, amoxicillin $(5 \mathrm{mg} / \mathrm{ml})$ and ciprofloxin $(5 \mathrm{mg} / \mathrm{ml})$. These are commonly used antibiotics to treat infections caused by several Gram-positive and Gramnegative bacteria. For each bacterial strain positive controls were maintained. The experiment was performed three times to minimize the error and the mean values are presented.

3.2c Minimal inhibition concentration: The compounds that exhibited considerable activity were diluted with nutrient broth (1:1) in a series of seven sets of three test tubes for different microorganisms. ${ }^{20}$ An aliquot of $1 \mathrm{ml}$ of the bacterial suspension $\left(1 \times 10^{6} \mathrm{CFU} / \mathrm{ml}\right)$ was inoculated into each tube. The control tubes were inoculated with same quantity of sterile distilled water and $75 \%$ ethanol. All tubes were incubated at $37^{\circ} \mathrm{C}$ for $24 \mathrm{~h}$. The lowest concentration that did not permit any visible growth when compared with the control was considered as the minimum inhibitory concentration. The contents of all tubes that showed no visible growth were cultured on nutrient agar, incubated at $37^{\circ} \mathrm{C}$ for $24 \mathrm{~h}$. The minimum bactericidal concentration was considered as the lowest concentration that could not produce a single bacterial colony.

The results of their antimicrobial screening of different compounds against different strains measured in $\mathrm{mm}$ were reported in table 2.

Also, the minimum Inhibitory concentration of compounds showing the potential activity in screening is given in table 3 .

Compounds 1c, 2d, 3d, 5d, 6a, 6b, 9, 9d were remained inactive i.e. have shown no activity against these seven bacterial strains. Control used was DMSO.

Table 3. Minimum inhibitory concentration of compounds showing the potential activity in screening.

\begin{tabular}{|c|c|c|c|c|c|c|c|}
\hline \multirow{2}{*}{$\begin{array}{l}\text { Sample } \\
\text { No. }\end{array}$} & \multicolumn{7}{|c|}{ Minimum Inhibitory Concentration $(\mu \mathrm{g} / \mathrm{ml})$} \\
\hline & P. fluorescence & S. typhimurium & S. aureus & E.coli & B. subtilis & S.epidermidis & A.calcoaceticus \\
\hline $1 \mathbf{a}$ & - & - & - & - & - & - & 28 \\
\hline $1 \mathbf{b}$ & 15 & - & 12 & - & - & - & 55 \\
\hline $2 \mathbf{a}$ & - & - & 14 & - & - & - & - \\
\hline $2 \mathbf{b}$ & 11 & 56 & - & - & - & - & - \\
\hline $2 c$ & 01 & - & - & - & - & - & - \\
\hline $3 \mathbf{a}$ & 25 & - & - & - & - & - & - \\
\hline $3 b$ & - & - & - & - & - & 47 & - \\
\hline $3 c$ & - & 23 & - & - & - & - & - \\
\hline $4 a$ & - & 27 & 54 & 01 & 02 & 02 & - \\
\hline $4 b$ & 14 & 01 & 06 & 17 & 21 & 13 & 36 \\
\hline $5 \mathbf{a}$ & - & 50 & - & - & - & 20 & - \\
\hline $7 \mathbf{a}$ & - & - & 12 & - & - & - & - \\
\hline $7 b$ & 14 & 28 & - & - & - & 46 & - \\
\hline $9 \mathrm{~b}$ & - & 13 & 26 & 54 & 50 & 20 & - \\
\hline
\end{tabular}

(-) : Showing no activity 


\section{Conclusions}

A one-pot synthetic method has been developed for 4aryl-1,3,4,5-tetrahydro- $2 H$-indeno[1,2- $d$ ]pyrimidine2-thiones using microwave irradiations. It can be concluded that microwave technology has proven to be better than conventional heating in the synthesis of these compounds as time and side products are decreased and yield is improved. We have succeeded in widening the scope of the first part of the reaction by using unconventional active methylene compounds.

The elucidation of structure-activity relationship shows that among all the indeno[1,2- $d]$ pyrimidine-2thiones evaluated for antibacterial activity, the thiones in which the hydroxyl group has been introduced in the 4-phenyl ring (4a and $\mathbf{4 b}$ ) show an increase in the bacteriostatic activity as compared to compounds $\mathbf{1 a}, \mathbf{1 b}$ and $\mathbf{1 c}$, which have only methoxy group in the 4-phenyl ring. Also, among $S$-alkylated/aralkylated derivatives, $S$-Ethyl (compound $\mathbf{4 b}$ ) and $S$-Methyl (compound $\mathbf{4 a}$ ) derivatives are the most potent. The $S$-Ethyl and $S$ Methyl moieties are present on the right hand side of the expected boat shaped structure of pyrimidine-2-thiones. This shows that we cannot ignore the structural details at right hand side as reported. ${ }^{18}$

\section{Acknowledgements}

Authors are thankful to Department of Chemistry and Department of Biotechnology, Punjabi University, Patiala for providing research facilities.

\section{References}

1. Biginelli P 1893 Gazz. Chem. Ital. 23360

2. Atwal K S, Rovnyak G C, Schwartz J, Moreland S, Hedberg A, Gougoutas J Z, Malley M F and Floyd D M 1990 J.Med Chem. 33(5) 1510

3. Kappe C O 1998 Molecules 31

4. Pathak P, Kaur R and Kaur B 2006 ARKIVOC xvi 160

5. Triggle D J and Janis R A 1987 Ann. Rev. Pharmacol and Toxicol, 27347

6. Sweet F and Fissekis J D 1973 J. Am. Chem. Soc. 95 8741

7. Kappe C O 1993 Tetrahedron 496937

8. Atwal K S, Rovnyak G C, O'Reilly B C and Schwartz J 1989 J. Org. Chem. 545898

9. Wendelin W, Schermanz K and Breitmaier E 1988 Monatshefte fuer Chemie 119, 355

10. Kaur B and Kaur R 2007 ARKIVOC xv 315

11. Edoh D and Alomatu B 2007 Comparison African J. Sci, Technol. 81

12. Lundin J I, Dargatz D A, Wagner B A, Lombard J E, Hill A E, Ladely S R and Fedorka- Cray P J 2008 Food Borne Pathogen Dis. 57

13. Nayak N, Nag T C, Satpathy G and Ray S B 2007 Ind. J. Med. Res. 125767

14. Masunari A and Tavares L C 2007 Bioorg. Med. Chem. 154229

15. Strahilevitz J, Truong-Bolduc Q C and Hooper D C 2005 Antimicrob. Agents Chemother. 495051

16. Wong K K Y and Hancock R E W 2000 J. Bacteriol. 82 2402

17. (a) Folkers K and Johnson T B 1933 J. Am. Chem. Soc. 55, 3784; (c) Kappe C O 1997 J. Org. Chem. 627201

18. Rana K, Kaur B and Kumar B 2004 Indian J Chem. 43B 1553

19. Perez C, Paul M and Bazerque P 1990 Acta Biol. Med. Exp. 15113

20. Aboaba O O, Smith S I and Olude F O 2006 Pakistan Journal of Nutrition $\mathbf{5} 325$ 